\title{
WEB-BASED EDUCATION ABOUT VULVODYNIA AND ITS CARE AMONG STUDENT HEALTHCARE STAFF: A QUASI-EXPERIMENTAL STUDY
}

\author{
Minna Törnävä $^{\mathrm{a}, \mathrm{b}, *}$, Meeri Koivula ${ }^{\mathrm{a}}$, Mika Helminen ${ }^{\mathrm{a}, \mathrm{b}}$, Tarja Suominen ${ }^{\mathrm{a}}$ \\ ${ }^{a}$ University of Tampere, Faculty of Social Sciences, Health Sciences \\ ${ }^{\mathrm{b}}$ Tampere University Hospital, Pirkanmaa Hospital District \\ *Corresponding author: Tampere University Hospital, Department of Physical and \\ Rehabilitation Medicine, PFYZ, PO Box 2000, 33521 Tampere, Finland. \\ E-mail addresses: minna.tornava@pshp.fi.
}

\section{ACKNOWLEDGMENTS}

The authors gratefully acknowledge the University of Tampere and Competitive State Research Financing of the Expert Responsibility area of Tampere University Hospital (9S069/9U060), Finland, for funding this study.

\section{Conflicts of interest}

The authors have all agreed to the byline order and to submission of the manuscript in this form. No conflict of interest has been declared by the authors.

\section{HIGHLIGHTS}

- Web-based education increased awareness and knowledge of vulvodynia and its care

- The impact of WBE on the subject was statistically and clinically significant

- WBE is a suitable form of education for nationwide student healthcare providers

- WBE is suitable for use by organisations that are geographically far from each other 


\begin{abstract}
$\underline{\text { ABSTRACT }}$
Student healthcare providers are the type of primary healthcare professionals who usually have first contact with young women who have problems with intimacy, such as vulvar pain - known as vulvodynia. However, a need to increase healthcare professionals' level of knowledge of vulvodynia and its care has been identified. This study aimed to assess the awareness and knowledge of vulvodynia and its care among student healthcare providers, before and after Web-based education. The study design was national, descriptive and quasi-experimental, and was conducted across Finland. A total of 79 participants completed baseline measurements, 58 completed web-based education and 30 took part in a follow-up survey. A survey instrument called 'Awareness and knowledge of vulvodynia and its care' was developed for this study, and the data were collected using a web-based questionnaire. Descriptive statistical methods were used to evaluate the participants' awareness and knowledge of vulvodynia and its care before and after web-based education. The primary results indicated that the participants' awareness and knowledge of vulvodynia and its care was statistically significantly improved following web-based education.
\end{abstract}

Keywords: Web-based education, student healthcare, vulvodynia, vulvar pain, women's health, awareness, knowledge, patient care management

\title{
1. INTRODUCTION
}

Vulvar pain with no clear aetiology is usually called vulvodynia, and it may result in numerous physical and psychosexual functional disorders in women (Goldstein and Burrows, 2008; Bohm-Starke, 2010; Sadownik, 2014). In Finland, student healthcare providers are the type of primary healthcare professionals who usually have first contact with young women who have problems with intimacy. However, women with vulvodynia have reported negative experiences with Finnish primary healthcare in terms of knowledge of the condition and its care (Törnävä et al., 2012). A recent study also found that the student healthcare providers who meet and care for 
females of fertile age have insufficient awareness and knowledge of vulvodynia and its care (Törnävä et al., 2017). To date, no study has evaluated the effectiveness of any type of education with regard to increasing the awareness and knowledge of vulvodynia and its care among healthcare providers.

\section{BACKGROUND}

\subsection{Web-based education}

Web-based education (WBE) is a cost-effective way of educating large numbers of healthcare providers, in terms of travel costs, as well as personnel time and trainer costs, enabling them to deliver the same consistent programme (Cook et al., 2010; Brown and Bullock, 2014; Lahti et al., 2014a). Well-designed WBE is also a dynamic, innovative and rich method of providing nursing staff with education on specific topics. It allows learners to access the particular website, follow lectures or complete assignments according to their own schedules, and the learners have sole control over the content, place and time of learning (Durkin, 2008; Cheng, 2012; Lahti et al., 2014a).

Evaluation of WBE interventions has shown that interactivity, practice exercises, repetition and feedback improve learning outcomes. A comparison of WBE intervention- and nonintervention-related knowledge has shown promising results in the medical field, although the findings have sometimes been contradictory (Cook et al., 2010; Lahti et al., 2014a). However, there remains a lack of evidence regarding the impact of WBE methods in nursing education (Lahti et al., 2014a).

\subsection{Vulvodynia and its care}

The International Society for the Study of Vulvar Diseases (ISSVD, 2016) defines vulvodynia as chronic pain or discomfort involving the vulva for more than 3 months, and for which no obvious aetiology can be found (Haefner, 2007). The exact causes of vulvodynia remain 
uncertain; however, previous studies have identified some possibilities, including inflammation, genetic factors, hormonal factors and contributory psychosocial factors (Goldstein and Burrows, 2008; Bohm-Starke, 2010; Danby and Margesson, 2010; Reed et al., 2014). Vulvodynia may be triggered during sexual intercourse and/or by nonsexual activities, such as wearing tight-fitting clothing or even sitting (Harlow and Stewart, 2003; Danby and Margesson, 2010; Sadownik, 2014). It can be classified according to the anatomical site of the pain; it may be localised to a specific area (localised vulvodynia) or to all over the vulva (generalised vulvodynia). It can also be categorised on the basis of whether the experienced pain is provoked or unprovoked (Haefner, 2007; Danby and Margesson, 2010; Sadownik, 2014). Localised, provoked vulvodynia is the most common form of the condition, and the patients are usually young nulliparous women. The lifetime prevalence of unexplained vulvar pain can be as high as 16\%; generalised, unprovoked vulvodynia is less common, with a 6-7\% prevalence. Generalised vulvodynia presents as a diffuse, constant, burning or raw pain anywhere on the genitals and/or the pelvic area. (Harlow et al., 2001; Danby and Margesson. 2010).

The lack of randomised trials means that the care of women with vulvodynia is primarily based on clinical experience, descriptive studies and reports made by expert committees. An individualised multidisciplinary approach is recommended to address both the physical and psychosexual aspects of the condition (Danby and Margesson, 2010; Nunns et al., 2010; ASCCP, 2016). It has been shown that such an approach increases women's knowledge of vulvodynia and helps them to gain the skills they need to address their pain, and also encourages them to take responsibility for their own care (Munday et al., 2007; Sadownik et al., 2012; Törnävä et al., 2012).

Counselling by healthcare personnel with regard to gentle self-care of the vulva area and other instructions to address pain is first-line treatment in minimising vulva irritation (Cox and Neville, 2012; Lindstrom and Kvist, 2015; ASCCP, 2016). It has also been shown that pelvic floor physiotherapy, such as biofeedback, electrical stimulation and pelvic floor manipulation, reduces 
pain in women with vulvodynia (Bergeron et al., 2001; Nunns et al., 2010; Melnik et al., 2012; Murina et al., 2013; Morin et al., 2016). Moreover, psychosexual interventions are effective in reducing vulvar pain and in improving associated psychosexual outcomes for these women and their partners (Bergeron et al., 2014; Davis et al., 2015). Medical interventions include topical, oral and injectable medical substances (Nunns et al., 2010; ASCCP, 2016); if conservative treatments have not been useful, and the pain is due to localised, provoked vulvodynia, a surgical procedure known as vestibulectomy may be effective (Andrews, 2011; Tommola et al., 2011).

\subsection{Knowledge of vulvodynia and its care}

Previous research into knowledge of vulvodynia and its treatment among healthcare professionals has primarily focused on the perspectives of either patients (Gordon et al., 2003; Buchan et al., 2007; Törnävä et al., 2012) or physicians (Updike and Wiesenfeld. 2005; Toeima and Nieto. 2011; Phillips et al., 2013); only one study also assessed the perspectives of nursing and therapy staff (Törnävä et al., 2017). The studies that investigated women's experiences of the care they received reported that the knowledge of healthcare staff was inadequate from the patients' perspective (Gordon et al., 2003; Buchan et al., 2007; Törnävä et al., 2012). In addition, an estimated $40 \%$ of women seeking treatment fail to receive help, and this estimate may even be conservative (Harlow and Stewart, 2003; Goldstein and Burrows. 2008).

It has been reported that junior gynaecologists have insufficient understanding of vulvodynia and its management (Toeima and Nieto, 2011), although Updike and Wiesenfeld (2005) and Phillips et al. (2013) reported a good awareness among obstetricians and gynaecologists. A recent study found that student healthcare providers who meet and care for women of fertile age have insufficient awareness and knowledge of vulvodynia and its care and, creation of educational programs was recommended to provide evidence-based care for women with the condition (Törnävä et al., 2017).

\section{$\underline{\text { 3. AIMS }}$}


The present study aimed to assess awareness and knowledge of vulvodynia and its care among student healthcare providers before and after WBE.

\section{METHODS}

\subsection{Design and sample}

The study design was national, descriptive and quasi-experimental, and it was conducted in student healthcare, which is part of primary healthcare in Finland. All student healthcare providers $(\mathrm{N}=191)$ who serve students of universities and other institutions of higher education, were chosen as the target group, and were recruited nationwide from all 12 student healthcare units. These individuals were invited to participate in the survey, and to receive WBE on vulvodynia and its care. They were invited via an email, which included information on the study, sent by the nurses in charge of the student healthcare units.

A baseline survey was conducted between February and April 2015. A letter reminding the participants of the follow-up survey was sent by the nurses in charge of the units at 2 , 4 and 6 weeks after the survey began. WBE on vulvodynia and its care was provided for a duration of 4 weeks, between October 2015 and November 2015. The follow-up survey was carried out 2 weeks after the completion of WBE, between December 2015 and February 2016.

\subsection{Survey instrument}

The web-based questionnaire consisted of individual background factors, demographic factors and three questions self-assessing each participant's own skills with regard to caring for women with vulvodynia (Table 1), as well as the "Awareness and knowledge of vulvodynia and its care' (AKVDC) survey instrument developed by the authors (Table 2). The latter consisted of two parts: 'Awareness of vulvodynia and its care' (Part 1) and 'Knowledge of vulvodynia and its care' (Part 2). Part 1 was developed on the basis of patient-related qualitative research findings on the care experiences of women with vulvodynia (Törnävä et al., 2012, 2013), 
while Part 2 was based on previous studies of vulvodynia (e.g. Bohm-Starke, 2010; Reed et al., 2014; Sadownik, 2014) and its management (e.g. Danby and Margesson, 2010; Nunns et al., 2010; Melnik et al., 2012).

Part 1 covers four main dimensions of awareness: the identification of vulvodynia (14 items), the treatment of vulvodynia (13 items), the significance of encountering patients (15 items) and the significance of providing information and support to patients (24 items). A 6-point Likert scale, ranging from 1 (completely disagree) to 6 (completely agree) or ranging from 1 (I know it remarkably poorly) to 6 (I know it remarkably well), was used to measure the participants' awareness.

Part 2 of the AKVDC instrument includes 20 items relating to the participants' knowledge of vulvodynia and its care. This part of the instrument is a knowledge test in which three possible options for the answers are given: true, false and not sure.

The face validity and content of the AKVDC instrument was tested in a pilot study by an independent panel of multi-professional healthcare staff $(\mathrm{N}=9)$, composed of uro/gynaecological nurses, pelvic floor physiotherapists, sex counsellors and gynaecologists, prior to the survey. They commented on the structure, phrasing, clarity, comprehensibility, relevance and assessment scale of the instrument. The instrument was modified as appropriate, in accordance with their work experience with women with vulvodynia.

The reliability of the AKVDC instrument was assessed using a pilot group of student healthcare staff $(\mathrm{N}=34)$, who were not part of the baseline and follow-up survey. The pilot study participants were asked to complete the questionnaire and to give feedback regarding any questions that were unclear. The internal reliability of Part 1 of the AKVDC was tested by calculating the Cronbach's alpha $(\alpha)$ for each subscale. Acceptable internal consistency $(\alpha>0.70)$ was found for all subscales, with the exception of 'awareness of the significance of meeting patients' $(\alpha=0.69)$. Thus, several questions under the dimension of awareness were clarified. Prior to the actual study 
with student healthcare providers, the instrument was modified and clarified on the basis of the pilot study. At baseline (Törnävä et al., 2017) and in the follow-up survey, all four subscales in Part 1 showed acceptable internal consistency (Table 2).

\subsection{Web-based education intervention}

WBE content on vulvodynia and its care, named 'Woman with vulvodynia - how should we take care of them?' was created by a multi-professional team of vulvodynia specialists, on the basis of previous studies (e.g. Danby and Margesson, 2010; Nunns et al., 2010; Reed et al., 2014; Sadownik, 2014) and clinical experience. This multi-professional healthcare team was composed of three uro/gynaecological nurses, two pelvic floor physiotherapists, one psychotherapist, two gynaecologists and one general practitioner. The educational content was created to follow the structure of the AKVDC instrument, and the areas of emphasis were established on the basis of the baseline survey (Törnävä et al., 2017).

WBE was provided via three modules in a Moodle virtual learning environment. Each of the three different modules were provided for the duration of 1 week, and took an estimated 1525 min for the participants to complete. For the purposes of the study, each module was opened separately, one-by-one. The module provided in the fourth week was a revision module, which gave the participants an opportunity to repeat the previous modules, if required. The WBE intervention included the text, anatomical pictures, videos of patient situations and the stories of women who had experienced vulvodynia. The participants also had the opportunity to contact the Web tutor if they experienced any technical problems with the learning environment. Table 3 shows the content and learning methods for each of the WBE modules.

\subsection{Ethical considerations}

The study protocol was approved by the board of trustees of the student healthcare administrative units. All the participants were sent an information letter by email, detailing the 
objectives of the study and explaining that completion of the Web-based survey implied their consent. The information letter also stated that participation in the surveys and WBE was voluntary, and that the survey was completely anonymous (Helsinki Declaration, 2013).

\subsection{Data analysis}

The Statistical Package for the Social Sciences for Windows, version 23 (IBM 2015), was used to analyse the data, and the Cronbach alpha score was used to calculate whether the aggregate of Part 1 of the AKVDC instrument was valid. The items in Part 1 were rated using a 6point Likert scale. The subscale scores were obtained by summing the responses given for each item and calculating the mean response. The averaged scores of the subscales created the total score for awareness, which was divided into six equal classes, as follows: 1.00-1.82 (extremely poor

awareness), 1.83-2.66 (poor awareness), 2.67-3.50 (somewhat poor awareness), 3.51-4.34 (somewhat good awareness), 4.35-5.18 (good awareness) and 5.19-6.00 (extremely good awareness). In order to calculate the participants' knowledge of the items in Part 2 of the AKVDC instrument, all correct answers were recorded as equal to 1; all wrong or uncertain answers were recoded as 0 . The data from the 20 questions were analysed by totalling all the answers given by each participant, resulting in an individual knowledge score of between 0 and 20.

Descriptive statistics using absolute (n) and relative (\%) frequencies were applied to analyse the categorical data, while the mean, median $(\mathrm{Md})$, quartile $(\mathrm{Q} 1, \mathrm{Q} 3)$ and interquartile range (IQR) were used to calculate the participants' awareness and knowledge of vulvodynia and its care. Fisher's exact test and the Mann-Whitney U test were used to analyse differences between baseline and the follow-up survey. A p value of $<0.05$ was considered statistically significant, and a $20 \%$ change in awareness and knowledge of vulvodynia and its care compared to baseline was considered clinically and statistically significant. 


\section{$\underline{\text { 5. RESULTS }}$}

\subsection{The demographics and the experience-based skills of the participants}

A total of 79 of the 191 healthcare providers in the student healthcare field participated in the baseline survey, resulting in a $41.4 \%$ response rate, while 58 participated in WBE on vulvodynia and its care, giving a $73.4 \%$ response rate. A total of 30 healthcare professionals in the baseline survey group participated in the follow-up survey, resulting in a $38.0 \%$ response rate. However, six of these individuals did not receive WBE on vulvodynia.

The demographic factors were not statically significant different compared to baseline. The majority of those who participated in the follow-up study were female (97\%), and were public health nurses (53\%) who worked according to a regular contract (93\%). Of those who completed the follow-up survey, 24 participated in the WBE on vulvodynia and its care. All experience-based skills were statistically significantly different compared to baseline. Following WBE, $63 \%$ of participants rated their skills as good in caring for women with vulvodynia, which was a statistically significant change from baseline, and $47 \%$ of participants also rated their skills as good in caring for vulvodynia couples, which was also a statistically significant change from baseline. Likewise, $90 \%$ of participants rated their skills as good in naturally discussing intimate issues after WBE, which was a statistically significant change from baseline (Table 1).

\subsection{Awareness and knowledge of vulvodynia and its care}

The awareness of how to identify vulvodynia among the participants who received WBE was 'good' $(\mathrm{Md}=5.07, \mathrm{IQR}=0.55)$, and was statistically significantly better $(\mathrm{p}<0.001)$ than at baseline. The awareness of treatments for vulvodynia was 'good' $(\mathrm{Md}=4.50, \mathrm{IQR}=0.50)$ after WBE. Compared to baseline, the measurements relating to that dimension were better at follow-up, and the difference was statistically significant $(\mathrm{p}<0.001)$. The awareness of the meaning of meeting patients was 'extremely good' $(\mathrm{Md}=5.40, \mathrm{IQR}=0.55)$ and statistically significantly better 
$(p=0.004)$ in the follow-up survey than at baseline. Moreover, The awareness of the meaning of received information and support was 'extremely good' $(\mathrm{Md}=5.58, \mathrm{IQR}=0.86)$ after $\mathrm{WBE}$ and statistically significantly better $(p=0.002)$ after WBE compared to baseline.

The knowledge of vulvodynia and its care was assessed via a 20 -item test. The mean of the correct answers across all of the data was 15.33 after WBE. There were statistically significantly more correct answers $(p<0.001)$ than there were before education (Table 4$)$.

\section{DISCUSSION}

The aim of this study was to assess the awareness and knowledge of vulvodynia and its care before and after WBE intervention among student healthcare providers. Moreover, an important goal was also to create and pilot a continuing WBE program on vulvodynia and its care for these individuals.

No study on the efficacy of any type of education program on the awareness or knowledge of vulvodynia and its care has previously been conducted among student healthcare professionals. However, on the basis of the present study, we may state that the WBE intervention is a suitable way of raising awareness and knowledge of the subject. Following WBE, a statistically and clinically significant increase in both awareness and knowledge was found in those who took received the education. A clinically significant change of greater than 1 point (20\%) in awareness of vulvodynia was observed, as measured via the AKVDC instrument (Part 1.) In this part of the instrument, the Md score of the awareness of vulvodynia and its identification and treatments increased by more than 1.2 points compared to baseline. Part 2 of the AKVDC consisted of the 20-item knowledge test, in which clinically relevant change was observed as $20 \%$, or a 4-point change in test score data. For those participants who received WBE, the mean knowledge test score rose by almost six points. Although the follow-up measurement also accounted for six people who were not involved in WBE, the awareness and knowledge of these individuals also increased slightly 
compared with the baseline measurement. The increase was not statistically significant, with the exception of the dimension of awareness of how to identify vulvodynia. Since these participants numbered only six, we cannot draw conclusions about changes in their awareness or knowledge.

We also found that the self-assessment questions relating to the skills required to care for women or couples with vulvodynia improved after WBE compared to baseline. The majority of previous WBE studies measured only a change in knowledge and/or the attitude towards a subject of education (Durkin, 2008; Eaton-Spiva and Day, 2011; Brown and Bullock, 2014). However, some studies found that it was possible to adopt new knowledge acquired from WBE and to transfer this knowledge to practice (Hart et al., 2008; Feng et al., 2013; Lahti et al., 2014b).

The student healthcare providers were permitted to participate in the WBE during their working hours. Nevertheless, the number of those who received the WBE and who participated in the follow-up assessments was small. It is possible that those individuals who did not take the time to receive the WBE considered it too time-consuming in addition to their own work. However, those who did receive the WBE conducted for each training module did so for a duration of 4 weeks. From this, we can draw a conclusion that this education was not too time-consuming for the participants. Another possible reason for lack of participation could be that some of the staff are not particularly familiar with WBE, which may have reduced the number of individuals who are receptive to this form of education. The exception to this is continuous pharmaceutical education, which nursing staff must receive at regular intervals (Finlex. 2010). In Finnish healthcare, only a few studies regarding the impact of WBE on topics other than pharmaceutical education have been conducted (Lahti, 2014; Lahti et al., 2014b). However, the receptivity of healthcare professionals to WBE has been studied to some extent, and it has been found that a software program that is perceived as 
useful, easy-to-use and enjoyable is important with regard to nurses' intention to use WBE (Cheng, 2012). The WBE platform used in the present study included the latterly mentioned elements, but it was not initially a familiar learning platform for all participants. If the WBE platform had been familiar to all, the receptivity rate might have been higher.

\section{$\underline{\text { 6.1. Limitations }}$}

Some limitations of this study are acknowledged. First, the AKVDC instrument was new and had only been used in a pilot test, a baseline survey and in this survey. The validity and reliability of this instrument warrant further testing with larger samples of healthcare professionals. Second, participation was voluntary and anonymous, in order to secure answers that were as honest as possible with regard to the participants' awareness and knowledge. It is possible that the recruited participants were already interested in the sexual health issues of young students, leading to the potential for selection bias in the results. Third, the reliance on self-reported measures might have led to common method bias, inflating the findings. Finally, participation in the baseline survey, WBE and the follow-up survey was poor. However, despite these drawbacks, this study provides some insights into the awareness and knowledge of vulvodynia and its care after WBE among student healthcare providers.

\subsection{Implications for practice}

Our study revealed a positive increase in awareness and knowledge of vulvodynia and its care after participation in a 4-week WBE program, entitled 'Women with vulvodynia - how should we take care of them?' Moreover, it also showed a positive effect on experienced-based skills with regard to caring for patients with intimacy problems. This WBE was specifically tailored to Finnish student healthcare, in which the units have a limited staff resource and are geographically far from each other. On the basis of the present study, this WBE program would also be a suitable and effective way of promoting continuing education 
in other primary healthcare organisations in addition to student healthcare. It has been shown that early intervention to address the symptoms of vulvodynia may prevent sexual and reproductive health problems in young women (Törnävä et al., 2013; Buchan et al., 2007). Likewise, early diagnosis and intervention regarding first care options in primary healthcare may also be beneficial to the patients themselves, as well as to society. In Finland, primary student healthcare providers are the type of healthcare professionals who usually have first contact with young women who have problems with intimacy. In this respect, it is important to consider the implications of an education program devoted to vulvodynia and its care for primary healthcare.

\subsection{Implications for research}

In the present study, the drop-out rate was unfortunately high, despite the fact that continuing education is recommended in Finnish healthcare (Finlex, 2003). Nevertheless, participation in such education is voluntary, and is influenced by personal, professional and organisational factors (Nalle et al., 2010). Furthermore, as part of continuing healthcare education, WBE is still in its infancy, and is associated with many uncertain factors. Further research should use a longitudinal analysis, considering the evolution of healthcare staff' acceptance of WBE over time.

\section{CONCLUSION}

WBE is an effective way of increasing awareness and knowledge of vulvodynia and its care among healthcare staff. It is a suitable form of staff education for big organisations that have many local units. The challenge of WBE lies in encouraging the staff to be receptive. 


\section{References}

ASCCP: American Society for Colposcopy and Cervical Pathology, 2016. Committee Opinion No 673: Persistent Vulvar Pain. Obstetrics \& Gynecology 128(3), e78-e84.

Andrews, J.C., 2011. Vulvodynia interventions--systematic review and evidence grading. Obstet.Gynecol.Surv. 66(5), 299-315.

Bergeron, S., Binik, Y.M., Khalife, S., Pagidas, K., Glazer, H.I., Meana, M., Amsel, R., 2001. A randomized comparison of group cognitive--behavioral therapy, surface electromyographic biofeedback, and vestibulectomy in the treatment of dyspareunia resulting from vulvar vestibulitis. Pain 91(3), 297-306.

Bergeron, S., Likes, W.M., Steben, M., 2014. Psychosexual aspects of vulvovaginal pain. Best Practice \& Research in Clinical Obstetrics \& Gynaecology 28(7), 991-999.

Bohm-Starke, N., 2010. Medical and physical predictors of localized provoked vulvodynia. Acta Obstet.Gynecol.Scand. 89(12), 1504-1510.

Brown, M., Bullock, A., 2014. Evaluating PLATO: postgraduate teaching and learning online. The clinical teacher 11(1), 10-14.

Buchan, A., Munday, P., Ravenhill, G., Wiggs, A., Brooks, F., 2007. A qualitative study of women with vulvodynia: I. The journey into treatment. J.Reprod.Med. 52(1), 15-18.

Cheng, Y.M., 2012. The effects of information systems quality on nurses' acceptance of the electronic learning system. Journal of Nursing Research 20(1), 19-30.

Cook, D.A., Garside, S., Levinson, A.J., Dupras, D.M., Montori, V.M., 2010. What do we mean by web-based learning? A systematic review of the variability of interventions. Med.Educ. 44(8), 765774.

Cox, K.J., Neville, C.E., 2012. Assessment and management options for women with vulvodynia. J.Midwifery Womens Health 57(3), 231-240.

Danby, C.S., Margesson, L.J., 2010. Approach to the diagnosis and treatment of vulvar pain. Dermatologic Therapy 23(5), 485-504.

Davis, S.N., Bergeron, S., Sadikaj, G., Corsini-Munt, S., Steben, M., 2015. Partner behavioral responses to pain mediate the relationship between partner pain cognitions and pain outcomes in women with provoked vestibulodynia. Journal of Pain 16(6), 549-557. 
Durkin, G.J., 2008. A comparison of the effectiveness of computer-based learning courses among nursing staff. Journal for Nurses in Staff Development - JNSD. 24(2), 62-66.

Eaton-Spiva, L., Day, A., 2011. Effectiveness of a computerized educational module on nurses' knowledge and confidence level related to diabetes. Journal for Nurses in Staff Development JNSD. 27(6), 285-289.

Feng, J., Chang, Y., Chang, H., Erdley, W.S., Lin, C., Chang, Y., 2013. Systematic review of effectiveness of situated e-learning on medical and nursing education. Worldviews on EvidenceBased Nursing 10(3), 174-183.

Finlex, Finland's Ministry of Justice, 2003. Finnish Statue on Continuing Vocational Education, 1194/2003. (Available at: http://www.finlex.fi/fi/laki/alkup/2003/20031194? search[type]= pika\&search[pika]=1194\%2F2003, accessed 11 January 2017)

Finlex, Finland's Ministry of Justice, 2010. Finnish statue on education needed to prescribe medication, $1089 / 2010$. (Available at: http://www.finlex.fi/fi/laki/alkup/2010/20101089?search[type] =pika\&search[pika]=1089\%2F2010, accessed 11 January 2017)

Goldstein, A.T., Burrows, L., 2008. Vulvodynia. Journal of Sexual Medicine 5(1), 5-14.

Gordon, A.S., Panahian-Jand, M., Mccomb, F., Melegari, C., Sharp, S., 2003. Characteristics of women with vulvar pain disorders: responses to a Web-based survey. J.Sex Marital Ther. 29(Suppl 1), 45-58.

Haefner, H.K., 2007. Report of the International Society for the Study of Vulvovaginal Disease terminology and classification of vulvodynia. Journal of Lower Genital Tract Disease 11(1), 48-49.

Harlow, B.L., Stewart, E.G., 2003. A population-based assessment of chronic unexplained vulvar pain: have we underestimated the prevalence of vulvodynia?. Journal of the American Medical Womens Association 58(2), 82-88.

Harlow, B.L., Wise, L.A., Stewart, E.G., 2001. Prevalence and predictors of chronic lower genital tract discomfort. American Journal of Obstetrics \& Gynecology 185(3), 545-550.

Hart, P., Eaton, L., Buckner, M., Morrow, B.N., Barrett, D.T., Fraser, D.D., Hooks, D., Sharrer, R.L., 2008. Effectiveness of a computer-based educational program on nurses' knowledge, attitude, and skill level related to evidence-based practice. Worldviews on Evidence-Based Nursing 5(2), 7584. 
Helsinki Declaration, 2013. WMA Declaration of Helsinki - Ethical Principles for Medical Research Involving Human Subjects. (Available at: http://www.wma.net/en/30publications/10policies/b3/, accessed 11 January 2017)

IBM: International Business Machines Corporation, 2015. Armonk, NY, USA. (Available at: https://www.ibm.com/products/spss-statistics, accessed 11 January 2017).

ISSVD: International Society for the Study of Vulvar Diseases, 2016. (Available at: http://www.issvd.org/resources/terminology/, accessed 11 January 2017).

Lahti, M., 2014. Evaluation of an e-learning course : coercion practices in psychiatric nursing. Annales Universitatis Turkuensis. Doctoral thesis. D.Medica-Odontologica (1121). Painosalama Oy - Turku, Finland 2014.

Lahti, M., Hatonen, H., Valimaki, M., 2014a. Impact of e-learning on nurses' and student nurses knowledge, skills, and satisfaction: a systematic review and meta-analysis. Int.J.Nurs.Stud. 51(1), 136-149.

Lahti, M., Kontio, R., Pitkanen, A., Valimaki, M., 2014b. Knowledge transfer from an e-learning course to clinical practice. Nurse Educ.Today 34(5), 842-847.

Lindstrom, S., Kvist, L.J., 2015. Treatment of Provoked Vulvodynia in a Swedish cohort using desensitization exercises and cognitive behavioral therapy. BMC Womens Health 15(108), DOI 10.1186/s12905-015-0265-3.

Melnik, T., Hawton, K., McGuire, H., 2012. Interventions for vaginismus. Cochrane Database of Systematic Reviews 12, 12:CD001760, doi: 10.1002/14651858.CD001760.pub2.

Morin, M., Dumoulin, C., Bergeron, S., Mayrand, M., Khalife, S., Waddell, G., Dubois, M., 2016. Provoked vestibulodynia (PVD) Study Group. Randomized clinical trial of multimodal physiotherapy treatment compared to overnight lidocaine ointment in women with provoked vestibulodynia: Design and methods. Contemporary Clinical Trials 46, 52-59.

Munday, P., Buchan, A., Ravenhill, G., Wiggs, A., Brooks, F., 2007. A qualitative study of women with vulvodynia: II. Response to a multidisciplinary approach to management. J.Reprod.Med. 52(1), 19-22.

Murina, F., Graziottin, A., Felice, R., Radici, G., Tognocchi, C., 2013. Vestibulodynia: synergy between palmitoylethanolamide + transpolydatin and transcutaneous electrical nerve stimulation. Journal of Lower Genital Tract Disease 17(2), 111-116. 
Nalle, M.A., Wyatt, T.H., Myers, C.R., 2010. Continuing education needs of nurses in a voluntary continuing nursing education state. J.Contin.Educ.Nurs. 41(3), 107-115.

Nunns, D., Mandal, D., Byrne, M., McLelland, J., Rani, R., Cullimore, J., Bansal, D., Brackenbury, F., Kirtschig, G., Wier, M., 2010. British Society for the Study of Vulval Disease (BSSVD) Guideline Group. Guidelines for the management of vulvodynia. Br.J.Dermatol. 162(6), 1180-1185.

Phillips, A., Large, E., Bird, M., Hitt, W., Eastham, D., Pulley, L., Hutchings, D., 2013. Vulvodynia in Arkansas: A Survey of Arkansas Gynecologists' Practice Experience and Management of Vulvar Pain. The Journal of the Arkansas Medical Society 109(10), 206-208.

Reed, B.D., Legocki, L.J., Plegue, M.A., Sen, A., Haefner, H.K., Harlow, S.D., 2014. Factors associated with vulvodynia incidence. Obstetrics \& Gynecology 123(2 Pt 1), 225-231.

Sadownik, L.A., 2014. Etiology, diagnosis, and clinical management of vulvodynia. International Journal of Women's Health 6, 437-449.

Sadownik, L.A., Seal, B.N., Brotto, L.A., 2012. Provoked vestibulodynia-women's experience of participating in a multidisciplinary vulvodynia program. Journal of Sexual Medicine 9(4), 10861093.

Toeima, E., Nieto, J., 2011. Junior doctors' understanding of vulval pain/vulvodynia: a qualitative survey. Archives of Gynecology \& Obstetrics 283(1), 101-104.

Tommola, P., Unkila-Kallio, L., Paavonen, J., 2011. Long-term follow up of posterior vestibulectomy for treating vulvar vestibulitis. Acta Obstet.Gynecol.Scand. 90(11), 1225-1231.

Törnävä, M., Koivula, M., Suominen, T., 2012. Vulvodyniaa sairastavien naisten hoitokokemuksia. (Care experiences of the women with vulvodynia). Tutkiva hoitotyö. 10, 32-39.

Törnävä, M., Koivula, M., Suominen, T., 2013. Naisten kokemuksia vulvodynian vaikutuksesta parisuhteeseen. (Women's experiences the effects of vulvodynia on the pair relationship). Hoitotiede. 25, 241-252.

Törnävä, M., Koivula, M., Helminen, M., Suominen, T., 2017. Women with vulvodynia: awareness and knowledge of its care among student healthcare staff. Scandinavian Journal of Caring Sciences. doi: $10.1111 /$ scs. 12455 .

Updike, G.M., Wiesenfeld, H.C., 2005. Insight into the treatment of vulvar pain: a survey of clinicians. American Journal of Obstetrics \& Gynecology 193(4), 1404-1409. 


\section{Table 1}

Demographic variables and experience-based skills of study participants

\begin{tabular}{|c|c|c|c|c|c|c|}
\hline \multirow[t]{2}{*}{ Demographic Variables } & & \multicolumn{2}{|c|}{ Baseline } & \multicolumn{2}{|c|}{ Follow-up } & \multirow[b]{2}{*}{$p$} \\
\hline & & $N$ & $(\%)$ & $N$ & $(\%)$ & \\
\hline \multirow[t]{2}{*}{ Gender } & Female & 74 & $(93.7)$ & 29 & $(96.7)$ & - \\
\hline & Male & 5 & $(6.3)$ & 1 & $(3.3)$ & \\
\hline \multirow[t]{3}{*}{ Age } & $27-40$ & 25 & (31.6) & 8 & $(26.7)$ & 0.895 \\
\hline & $41-53$ & 26 & (32.9) & 11 & $(36.7)$ & \\
\hline & $54-65$ & 28 & $(35.4)$ & 11 & $(36.7)$ & \\
\hline \multirow{3}{*}{$\begin{array}{l}\text { Years of work experience } \\
\text { in health care }\end{array}$} & $1-14$ & 24 & $(30.4)$ & 7 & $(23.3)$ & 0.662 \\
\hline & $15-27$ & 28 & $(35.4)$ & 10 & (33.3) & \\
\hline & $28-40$ & 27 & $(34.2)$ & 13 & $(43.3)$ & \\
\hline \multicolumn{7}{|l|}{ Education } \\
\hline \multicolumn{2}{|c|}{ Nursing and therapy staff } & 57 & & 23 & & 0.809 \\
\hline & Public health nurse & 33 & $(41.8)$ & 16 & $(53.3)$ & \\
\hline & Registered nurse & 4 & $(5.1)$ & 1 & (3.3) & \\
\hline & Psychologist & 11 & (13.9) & 3 & $(10.0)$ & \\
\hline & Physiotherapist & 4 & $(5.1)$ & 2 & $(6.7)$ & \\
\hline & Other & 5 & $(6.3)$ & 1 & $(3.3)$ & \\
\hline \multicolumn{2}{|c|}{ Physician staff } & 22 & & 7 & & \\
\hline & Physician & 22 & $(27.8)$ & 7 & $(23.7)$ & \\
\hline \multirow[t]{3}{*}{ Type of job contract } & Regular & 68 & $(86.1)$ & 28 & $(93.3)$ & - \\
\hline & Fixed-term & 10 & (12.6) & 2 & $(6.7)$ & \\
\hline & Hourly & 1 & $(1.3)$ & 0 & & \\
\hline Specialization in & Yes & 11 & $(13.9)$ & 5 & $(83.3)$ & 0.765 \\
\hline Sexology & No & 68 & $(85.1)$ & 25 & $(16,7)$ & \\
\hline \multirow{3}{*}{$\begin{array}{l}\text { Frequency of meetings } \\
\text { with VD patients }\end{array}$} & Never & 14 & $(17.7)$ & 2 & $(6.7)$ & 0.370 \\
\hline & $<1 \times$ a month & 50 & $(63.3)$ & 22 & $(73.3)$ & \\
\hline & $\geq 1 \mathrm{x}$ a month & 15 & $(19.0)$ & 6 & $(20.0)$ & \\
\hline \multicolumn{7}{|l|}{ Experienced-based skills in } \\
\hline \multirow[t]{2}{*}{ taking care of VD patients } & Poor (scale of $1-3$ ) & 60 & $(75.9)$ & 11 & $(36.7)$ & $<0.001$ \\
\hline & Good (scale of 4-6) & 19 & $(24.1)$ & 19 & $(63.3)$ & \\
\hline \multirow[t]{2}{*}{ taking care of VD couples } & Poor (scale of 1-3) & 64 & $(81.0)$ & 16 & $(53.3)$ & 0.007 \\
\hline & Good (scale of 4-6) & 15 & $(19.0)$ & 14 & $(46.7)$ & \\
\hline \multirow{2}{*}{$\begin{array}{l}\text { naturally discussing intimate } \\
\text { issues }\end{array}$} & Poor (scale of $1-3$ ) & 36 & $(45.6)$ & 3 & $(10.0)$ & 0.001 \\
\hline & Good (scale of 4-6) & 43 & $(54.4)$ & 27 & $(90.0)$ & \\
\hline
\end{tabular}

$p=$ Fisher's Exat Test (2-sided), VD = vulvodynia. 
Table 2 The Awareness and Knowledge of Vulvodynia and its Care (AKVDC) survey instrument

\begin{tabular}{|c|c|c|c|c|c|}
\hline AKVDC & Items & Answering scale & & & \\
\hline Part 1: & 66 & A 6-point Likert scale & The $C$ & onbach & alpha \\
\hline Awareness of & & $\begin{array}{l}\text { to } 6=\text { completely agree } \mathrm{OR} \\
\text { From } 1=\mathrm{I} \text { know it remarkably poorly } \\
\text { to } 6=\mathrm{I} \text { know it remarkably well }\end{array}$ & $\alpha \mathrm{P}$ & $\alpha 0$ & $\alpha \mathrm{F}$ \\
\hline how to identify VD & 14 & & 0.81 & 0.83 & 0.84 \\
\hline the treatments for VD & 13 & & 0.78 & 0.80 & 0.72 \\
\hline $\begin{array}{l}\text { the significance of encountering } \\
\text { VD patients }\end{array}$ & 15 & & 0.69 & 0.89 & 0.92 \\
\hline $\begin{array}{l}\text { the significance of providing } \\
\text { information and support to VD patients }\end{array}$ & 24 & & 0.86 & 0.91 & 0.95 \\
\hline
\end{tabular}

Part 2: Knowledge of VD and its care $\quad 20 \quad$ True, false or unsure

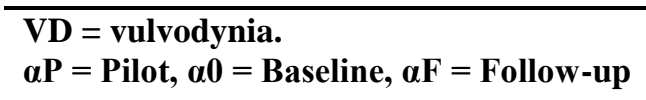

Table 3 Content and learning methods of web-based education on vulvodynia and its care.

The WBE intervention: Woman with vulvodynia - how should we take care of them?

\begin{tabular}{|c|c|c|c|}
\hline Week & Module & Educational content & Learning methods \\
\hline 1 & 1 & $\begin{array}{l}\text { Introduction to WBE } \\
\text { How to identify VD }\end{array}$ & $\begin{array}{l}\text { Text } \\
\text { Anatomical pictures } \\
\text { Experiences of women with VD } \\
\text { Tutoring of technical issues }\end{array}$ \\
\hline 2 & 2 & $\begin{array}{ll}\text { Treatments for VD } \\
\text { • } & \text { Self-care } \\
\text { - } & \text { Psychosexual interventions }\end{array}$ & $\begin{array}{l}\text { Text } \\
\text { Anatomical pictures } \\
\text { Experiences of women with VD } \\
\text { Videos of a patient situations } \\
\text { Tutoring of technical issues }\end{array}$ \\
\hline 3 & 3 & $\begin{array}{l}\text { Treatments for VD } \\
\text { - Physiotherapy } \\
\text { - Medical interventions } \\
\text { The significance of encountering VD patients } \\
\text { The significance of receiving information and } \\
\text { support to VD patients }\end{array}$ & $\begin{array}{l}\text { Text } \\
\text { Anatomical pictures } \\
\text { Experiences of women with VD } \\
\text { Video of a patient situation } \\
\text { Tutoring of technical issues }\end{array}$ \\
\hline 4 & $1-3$ & Revision & Revision \\
\hline
\end{tabular}

$\mathrm{WBE}=\mathrm{Web}$-based education, $\mathrm{VD}=$ vulvodynia 
Table 4

Awareness and Knowledge of Vulvodynia and its Care on baseline and on follow-up

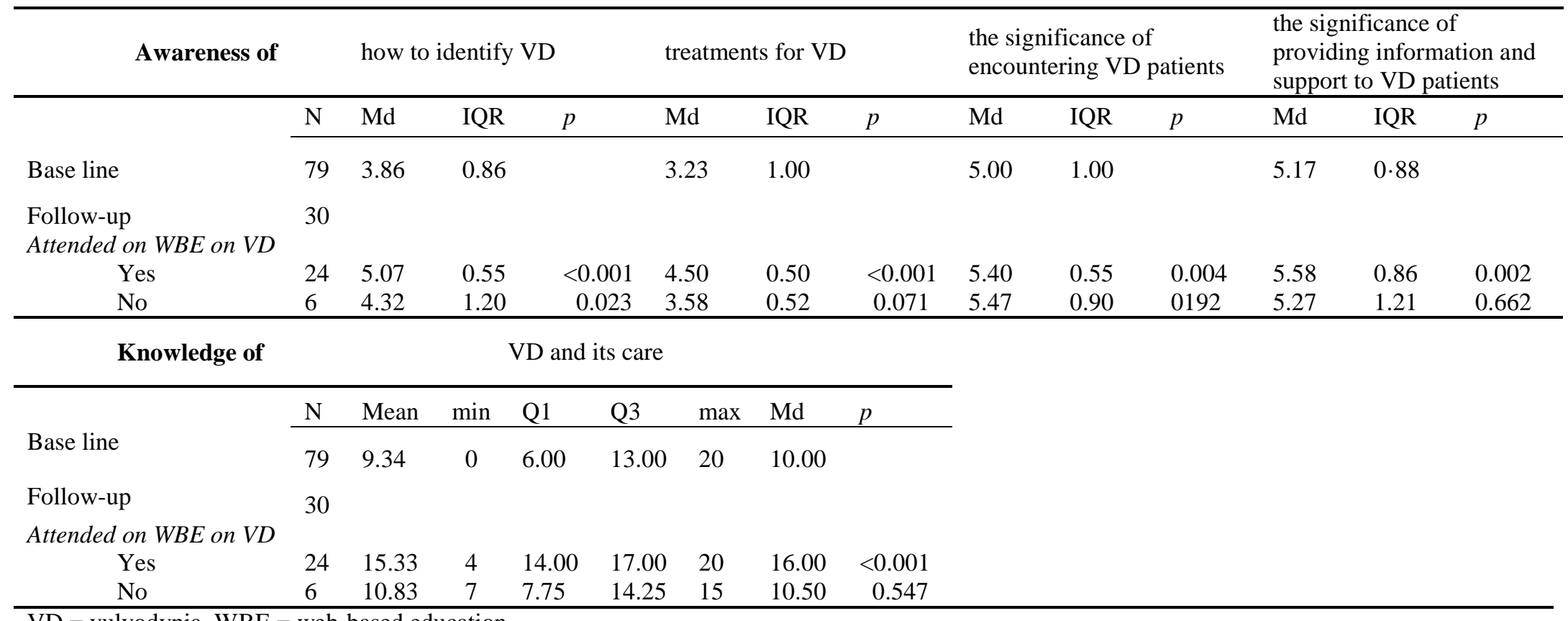

VD = vulvodynia, WBE = web-based education.

$\mathrm{Md}=$ Median, $\mathrm{IQR}=$ Interquartile range, $\min =$ Minimum, $\mathrm{Q}=$ quartiles, $\max =$ Maximum . 